\title{
Ontologia da liberdade na rede: a guerra das narrativas na internet e a luta social na democracia
}

\begin{abstract}
RESUMO
Esse artigo visa, em retrospectiva, analisar os fundamentos políticos que regem os discursos de liberdade que são disseminados pelos atores que constroem a internet de hoje e de ontem. Esta análise visa extrair um modo de compreender a economia do poder em disputa, instaurada pelos diferentes atores em conflito da sociedade em rede. Para tanto vamos avaliar os processos de narração coletiva dos acontecimentos públicos, entendidos como laboratórios dessas disputas. Desta avaliação vai emergir que as novas narrativas multitudinárias vão fazer a passagem do modelo informacional das mídias, que privilegia a acumulação quantitativa proprietária de elementos, para o modelo comunicacional das multimídias, que privilegia a coordenação da ação coletiva nos movimentos.
\end{abstract}

\section{PALAVRAS-CHAVE}

Acontecimento

Biopolítica

Cibercultura

\begin{abstract}
This paper aims to analyze in retrospect the political foundations that rule the discourses of freedom spread by the agents who build the Internet yesterday and today. This analyze trace a way to understand the struggle's power economy made by the different agents in conflict in the network society. We are going to evaluate the processes of collective discourse of public events, understood as laboratories of this struggles. From this evaluation will raise the new multitudinary discourse as a road doing the passage of informational model, with its privilege of quantitative accumulation of owner elements, to the communicational model of multi-medias that privilege the collective action coordination in the social movements.
\end{abstract}

\section{KEYWORDS}

Event

Biopolitic

Cyberculture

\author{
Henrique Antoun \\ Professor do Programa de Pós-Graduação em Comunicação da UFRJ/RJ/BR. \\ henrique.antoun@eco.ufri.br
}

\section{Fábio Malini}

Professor do Departamento de Comunicação da UFES/ES/BR.

fabiomalini@gmail.com 
Na década de 1990, o uso da internet, associado às dinâmicas de produção e consumo de portais, transformou a rede num enorme laboratório da publicidade. E, de certa forma, a dinâmica de fragmentação, legitimada pela infinidade de redes de pequenos mundos centralizados, empurrava a web para uma experiência majoritariamente baseada no download de sites, que deveriam - dentro da utopia de felicidade eterna da nova economia - se revelar, antes, como start ups de modelos empresariais do capitalismo de risco.

A internet de hoje se transmutou, sem dúvida. A atuação social, a mobilização e o engajamento viraram um valor da rede, se contrapondo àquele pensamento de felicidade eterna da web comercial, que contaminava a economia e a política. Em grande medida, essa metamorfose está ligada à emergência das dinâmicas ativistas, presentes já no final dos anos 90, que resgataram o sentido originário do peer to peer na internet. Este resgate deu à rede um novo uso ao promover diversas inovações que vão do Napster ao Pirate Bay, dos blogs aos mashups, dos sistemas de troca de arquivo às mídias sociais colaborativas, do jornalismo cidadão neozapatista à tuitagem iraniana.

\section{A internet de hoje se transmutou, sem dúvida.} A atuação social, a mobilização e o engajamento viraram um valor da rede, se contrapondo àquele pensamento de felicidade eterna da web comercial, que contaminava a economia e a política.

A emergência destas inovações gerou todo um conjunto novo de disputas e conflitos sobre a produção e a regulação da liberdade na internet, pois todo o valor no capitalismo cognitivo está radicado em fazer os conectados livres permanecerem dentro dos limites programáveis e das conexões pré-estabelecidas nas interfaces, para recolher da multidão toda a sua produção social. É o paradigma do "tudo é meu" na produção colaborativa (Malini, 2008). Na contra mão deste movimento de retenção, há outro que visa inflar de liberdade a rede, a partir da disseminação de dispositivos aceleradores da socialização e do compartilhamento de conhecimentos, informação e dados, seguindo novos modelos de direito público. Estas ações coletivas de disseminação abrem um conflito com a governança capitalista da liberdade na rede.
A partir destas transformações da comunicação em rede vai emergir o choque de poderes entre as mídias de massa e as interfaces de usuários como um fato inegável. A mídia irradiada cada vez mais ressalta seu poder de atingir uma quantidade imensa de populações em uma só tacada, para ressaltar a virtude mantenedora de sua sustentação financeira. Do ponto de vista da formação cultural, porém, a produção de subjetividade da mídia massiva esbarra em seu produto mais notório: os fans - esses pequenos fanáticos com momentâneas opiniões compactas disseminados em profusão pelo poder da irradiação (Jenkins, 2006). Ela só consegue produzir seus efeitos em prazo curto, gerando estes pequenos fanatismos oscilantes em torno de suas causas. Desde o seu surgimento, a mídia distribuída tem se contraposto através de seus usuários a estes efeitos acachapantes de achatamento da diversidade cultural promovida pelos processos de indução e falseamento de opinião típicos desta comunicação unilateral onde poucos falam para muitíssimos.

Embora a mídia irradiada de massa seja uma valiosa máquina de construção e destruição instantânea de reputação social; as mídias distribuídas de coletivos tem se revelado uma poderosa máquina de criação e sustentação de reputação duradoura, funcionando em longo prazo. Enquanto a mídia massiva extrai seu poder da sensação de "todo mundo esta falando isso" subentendido em seu uníssono; as interfaces de usuários encontram o seu poder ancorado na sensação de "meus amigos recomendam" vinculado à suposta confiabilidade da fonte da comunicação.

Esse artigo visa, em retrospectiva, analisar os fundamentos políticos que regem os discursos de liberdade que são disseminados pelos atores que constroem a internet de hoje e de ontem. Esta análise visa extrair um modo de compreender a economia do poder em disputa, instaurada pelos diferentes atores em conflito da sociedade em rede. Para tanto vamos avaliar os processos de narração coletiva dos movimentos sociais nos acontecimentos públicos, entendidos como laboratórios dessas disputas. Desta avaliação vai ser proposto que as novas narrativas multitudinárias vão fazer a passagem do modelo informacional das mídias - que privilegia a acumulação quantitativa proprietária de elementos narrativos - para o modelo comunicacional das multimídias, que privilegia a coordenação da ação coletiva através da conversação atual durante os movimentos. 


\section{Biopoder na internet: a liberdade negativa da fábrica social}

A internet é um campo social, como muitos outros, onde a liberdade está em disputa. Na verdade, quando dizemos "liberdade" entende-se aí os mecanismos e atos autônomos de cooperação social que permitem o exercício do poder (e do contrapoder), a produção social e a ativação de afetos geradores da psicologia. Em certo sentido, essa definição complementa a acepção spinosista do homem livre como sendo aquele que se realiza na sociedade civil, onde se vive de acordo com leis comuns, e não na solidão e no isolamento, onde se obedece apenas a si mesmo.

A liberdade assim pensada está longe de se esgotar no sentido liberal de "direito de ter propriedade" (de ideias, de mercado, de terras, etc.), ou de "ter força para suplantar o outro" como quer o sentido hobbesiano. Hoje o cerne do debate sobre liberdade está no direito de produção autônoma de formas de vida, que não sejam atravessadas pela força estatal, nem pela mercantilização do capital, mas por "direitos comuns" que as protejam e as liberem ao mesmo tempo. Não é à toa que o movimento social mais importante da primeira década do século XXI foi a disputa pelo controle dessa produção comum protegida e partilhada. Disputas endógenas ao capital - como a que contrapõe o Google à Microsoft exprimindo a forte tensão entre a computação em nuvem e a indústria do licenciamento - e exógenas a ele - a disputa entre a cultura da colaboração peer-to-peer e a cultura da permissão proprietária.

$\mathrm{Na}$ internet se percebe um vasto movimento de redução da oferta de liberdade (travestida de inflação), vinculado às medidas de cercamento (enclosures) da liberdade nos sistemas controlados de informação - o império da liberdade mercantilizada na rede. Neste sentido, tal como analisa Castells (2009, p. 421), os dispositivos da web 2.0 vão se transformar em estupendos instrumentos de negócios através da estratégia de mercantilização da liberdade para a acumulação de capital. Deste modo vão realizar o "cercamento" (enclosure) da terra comum da comunicação livre, vendendo às pessoas o acesso aos produtos da comunicação global em rede em troca de sua renúncia à sua privacidade e da sua conversão em arco e alvo da seta publicitária.

Essa mercantilização da vida - das conversas e quadros da vida contidos na internet -, guarda relação com o debate aberto por Foucault sobre uma nova arte de governar a liberdade dos sujei- tos, chamada por ele de biopoder. Ela investiria na vida como um todo, ativando-a e a pondo a atuar. O biopoder operaria com mecanismos que têm por função "produzir, insuflar, ampliar as liberdades, introduzir um 'a mais' de liberdade por meio de um 'a mais' de controle e de intervenção" (Foucault, 2008a, p. 92). Na lógica instaurada por ele, já não se governa somente o corpo das populações. Torna-se objeto de governo todo o meio ambiente, a comunicação, os conhecimentos e os afetos das populações.

Esse governo se exerce através da geração incessante de riscos tanto para limitar a independência (portanto, a ação livre); quanto para expandir o medo. Os riscos e suas vítimas e algozes virtuais fazem aceitáveis os discursos e as práticas de segurança, geradores das comunidades ou dos guetos. A sociedade dos perfis da internet é um bom exemplo disso, pois a sua configuração dilui o comum, valorizando a personalidade e as egolatrias. Será igualmente sobrevalorizada a segurança informacional, através do discurso da "credibilidade da informação" da grande mídia e seus gatekeepers em oposição à multiplicidade dos pontos de vista tecidos na cobertura informativa dos acontecimentos sociais por milhares de sujeitos na rede através de blogs e redes sociais. Esta multidão de desconhecidos produz uma cobertura dos acontecimentos através de conversações singulares próprias, logo estigmatizadas como produto de amadores, de falsas individualidades ou de anônimos irresponsáveis.

A liberdade na rede - para aqueles que querem transformá-la em commoditie 2.0, é uma liberdade negativa, pois concebida como uma liberdade regulada por leis de direito autorais e propriedade intelectual, autorizando a realização do sonho fordista das corporações de mídia: “transformar-se em grande fábrica que monitora as atividades de todos online" (Barbrook, 2003). E com isso são capazes de mobilizar um biopoder produtor de discursos, práticas cotidianas, atitudes e processos de aprendizagem constituídos nas máquinas participativas da internet.

Essa estratégia das corporações de mídia online acaba por intensificar a cultura dos fãs, que povoa a internet com a reprodução dos bordões e temas disseminados nos canais da mídia massa, ocupando a rede participativa com assuntos do momento e uma agenda social efêmera e especular. A profusão dos sites de fãs de ídolos e programas da cultura de massa, as conversas recorrentes sobre os temas das TVs e grandes jornais, e 
as repetições em cascata de bordões e ritornelos propagandísticos erguem um gigantesco tsunami onde se guarda a maior parte do que existe na internet (Jenkins, 2006), em tudo distante da recombinação criadora e da atitude libertária preconizada em vários mantras (Terranova, 2004).

Além de mídias de fãs e celebridades, a internet participativa se vê mergulhada na lógica dos "pequenos Roberto Marinho" - uma classe de (micro) blogueiros e perfís de redes sociais cuja principal tarefa será a de caçar usuários páraquedistas, pautando-se exclusivamente por assuntos do momento e por trocas incestuosas de links com outros blogueiros. Eles criam um campo restrito de perspectivas e configuram uma ecologia na qual as ideias e as informações são sempre as mesmas através de diferentes blogs.

$\mathrm{Na}$ verdade, trata-se de uma estratégia de extrair vantagens financeiras, publicitárias e de audiência, que transbordará, depois, na busca por modelos de negócio baseados na reunião desses micro pop stars da irrelevância online. Eles funcionam como pequenas árvores aproveitando-se de pequenos rizomas, à medida que centralizam uma acumulação (de capital de todo o tipo) que traga para si os dividendos políticos e monetários dessa cultura massiva dos fãs online, gerando comunidades virtuais que funcionam através de efeitos especiais e imagens narcisistas.

O efeito colateral dessa "liberdade negativa", promovida pelas corporações de mídia online, será a propriedade e a fragmentação dos bens comuns, para além de uma busca incessante pela produção de repetições balbuciantes dos fãs online. Nessa perspectiva, a cultura se vê ameaçada pelos códigos de copyright estabelecidos pelo capital midiático, ditando os modos pelos quais os bens culturais devem circular e serem usados. Na onda 2.0, dá-se com uma mão para se retirar com a outra.

"Nunca o copyright protegeu um leque tão amplo de direitos, contra um leque tão amplo de atores, por um tempo tão longo" (Lessig, 2005). Ao ponto dos conteúdos produzidos pelos cidadãos tornarem-se propriedade intelectual dos proprietários dos sites colaborativos da internet. Exercido por uma multiplicidade de sujeitos, o poder de criar em rede - a colaboração - vai sendo cada vez mais freado pelo poder de cobrar para que se crie em rede - a permissão. Essa usurpação praticada pelos oligopólios industriais da cultura e da mídia instaura uma espécie de feudalismo digital, onde o usuário da inter- net torna-se um internauta preso à terra que ele mesmo povoou. Isto corrobora a visão de Negri e Hardt (2005), quando sustentam o poder redutor da capacidade de cooperação e de comunicação promovida pela propriedade privada dos bens informacionais.

Essas capacidades são as bases da inovação numa economia onde o valor se concentra na qualidade imaterial do trabalho, ou seja, na competência de incorporar nos processos e nos produtos a informação, a cultura e o afeto. A crítica brota da constatação do valor cooperativo do trabalho imaterial, tornando impossível para o seu produto se limitar a ser propriedade um único indivíduo, ao invés de pertencer a uma atividade comum cooperativa. Embora a internet em sua configuração econômica atual veicule uma ideologia de liberdade desregulada, na prática ela é subsumida por arquiteturas e protocolos que mantém a cultura sobredeterminada por um biopoder estimulador da criação de subjetividades.

Por isso, embora haja verdade na conversa em torno da Web $2.0 \mathrm{com}$ seus blogs, wikis, folksonomics, YouTubes e redes sociais; ela dificilmente coincidiria com a opinião veiculada pelos apólogos da internet sobre o significado da mudança na comunicação e nos negócios. Na nova web, eles anunciam, a publicidade encontraria a nova voz dos grupos da cultura da mídia, um público auto organizado e participativo que a transformariam em uma honesta recomendação crítica dos usuários.

Os usuários se transformariam em sócios das empresas através de sua cooperação interessada e a colaboração e a livre expressão uniria empresários e usuários nesse poderoso ambiente de negócios integrados (Levine; Locke; Searls e Weinberger, 2000). Mesmo o quadro de idílio parecendo atraente, basta que os interesses das empresas se vejam ameaçados por iniciativas dos usuários para o conflito explodir e o confronto aparecer em toda sua violência (Antoun; Lemos e Pecini, 2007).

\section{A liberdade positiva, ou a biopolítica na rede}

A existência de um biopoder midiático na internet, que controla a vida e se apropria da riqueza produzida em comum nas redes mais avançadas de computação em nuvem, não significa entoar um refrão apocalíptico que expresse somente a subsunção da vida no capital. Isso porque o trabalho imaterial da multidão não se esgota numa relação de comando ao biopoder. 
Todo processo de dominação encontra um limite, que pode se transformar em resistência. Nesse sentido, a biopolítica é a potência de a vida governar-se nos espaços onde se desenvolvem lutas, relações e produções de poder; enquanto o biopoder é um poder contra a autonomia da vida, procurando fazê-la submeter-se aos centros transcendentes de governo.

A biopolítica é o conjunto de atos de resistência e de contra insurgência de vidas que não aceitam a captura do controle e reivindicam uma economia da cooperação mantenedora dos bens comuns dentro de um direito e de um espaço público, para além da noção de que este deva ser regulado e garantido por um estado, portanto, por um agente de força exterior às singularidades anárquicas da multidão. Longe de ser uma experiência de anarquia, trata-se de uma experiência democrática constituída por direitos sempre abertos e potencializadores da liberdade.

Na prática, num momento em que o biopoder cria e programa redes de captura do comum, não é de se estranhar o surgimento das redes de contrapoder funcionando da mesma forma, ou seja, criando e programando redes autônomas, antecipando novos direitos e desejando a democracia. Em sua teorização, Antonio Negri (2003) associa a biopolítica "como a representação material da capacidade do trabalho vivo (imaterial) de apresentar-se como excedente". Isso significa que, mesmo em regime de comando pós-moderno de destruição do comum e expropriação da cooperação, o trabalho imaterial excede o biopoder, porque pode ser realizado fora de uma relação de comando empresarial.

O trabalho imaterial produz resultados, no campo da inovação e da linguagem, por exemplo, que não ficam encarnados exclusivamente na empresa, mas diluídos em cada uma das singularidades que cooperaram para produzi-los. Daí muitos autores problematizarem a dimensão biopolítica da cópia, para além da fobia autoral capitalista, pois ela é ao mesmo tempo a condição para constituição de novos valores de uso, e também de novos valores de troca.

O capitalismo das redes se vê jogado desta maneira para uma infindável contradição, pois sem socialização das cópias não há novos usos criativos, e sem novos usos criativos não há geração de valor de troca. Talvez o fenômeno biopolítico mais intenso seja o movimento de compartilhamento de arquivos peer to peer na internet, pois ele foi capaz de fazer arquiteturas de uso à prova do controle do biopoder, numa espécie de darwinismo tecnológico do bem.

\section{A guerra das narrativas e a luta social na democracia}

Podemos pensar que o poder da mídia de massa deixou de ser um poder moderno, sob a forma de uma ação sobre a ação presente, para se tornar um poder de controle, investindo a ação sobre a ação futura (Deleuze, 1992; Foucault, 2008). Mais do que um lugar disciplinar de irradiação e circulação de palavras de ordem (Deleuze; Guattari, 1980; Foucault, 1977), ele se revela como um poder de atualização da memória nas comunicações.

No caso da mídia massiva trata-se de um monopólio sobre a atualização das informações; um poder de mobilizar, processar e narrar o passado, tornando-o atual. A massa só pode acessar o passado comum através das atualizações feitas pela grande mídia corporativa. Isto configura um imenso poder sobre os mecanismos de lembrança e esquecimento social das populações. Através dele eu relaciono um passado qualquer com um acontecimento da atualidade para balizar a decisão de agir do sujeito social.

Este passado vai ser apresentado sob a forma de grafos e diagramas, dando foros de previsibilidade às imagens estratigráficas do que já foi que se transforma desta maneira em um será. Este passado é atualizado para mobilizar as esferas de decisão e ação social sendo preferencialmente investido para endossar ou inibir os programas eleitorais de candidatos a cargos executivos, as imagens públicas de candidatos majoritários em épocas de eleição e às discussões legais acopladas a decisões parlamentares para criação ou transformação de leis existentes.

A entrada em cena da internet veio quebrar esse monopólio da narração. Através de suas interfaces qualquer usuário podia tornar atualizável qualquer informação, liberando sua comunicação. $\mathrm{O}$ investimento comunicacional dos movimentos sociais e coletivos passava a responder pelo alcance ou frequência de uma informação qualquer, conectando entre si diferentes interfaces e promovendo sua disseminação (Antoun, 2004). Não só os usuários podem conectar qualquer informação antiga que esteja na rede com uma atual; como eles podem determinar o alcance de uma informação atual, replicando-a por diferentes interfaces. A comunicação partilhada nas interfaces coletivas de parceria (peer to peer) 
reposiciona o tipo de passado que importa na decisão de ação.

A estatística preditiva das imagens estratigráficas cede lugar aos projetos comuns dos coletivos comunicacionais. A questão deixa de ser a eliminação do que nos ameaça para se tornar a construção ou invenção do que nos interessa (Antoun, Lemos e Pecini, 2007). É, nesse sentido, que essa biopolítica da rede se ativa como uma liberdade positiva, no sentido que essa atividade dos usuários, de construírem de forma singular, e nem por isso disputado, conflitivo e contraditório, um campo mais extenso dos significados dos acontecimentos sociais, em que entrelaçam narrativas que esmiúçam fatos, ideias dados, imagens, que ampliam a capacidade da rede de revelar sentidos que até então se reprimia na lógica gatekeeper dos mídias online tradicionais, com a sua política para internet baseada na lógica do olhe, mas não toque, em que desacreditar e descredenciar as mídias participativa dos usuários.

Importante assinalar a perda do monopólio da edição e reprodução das falas e imagens pelas TVs e demais mídias massivas. O poder de atualização das imagens dos blogs, do YouTube e do Twitter proporcionado a seus usuários deu um diferente alcance às suas narrativas. Podendo escolher o que atualizar das imagens disponíveis para narrar o acontecimento e conversar, a mídia livre pôde decidir a quem imputar a responsabilidade pelo conflito. As imagens e os discursos feitos pelas mídias de massa uma vez reproduzidos e analisados e reutilizados se revelavam apropriadas para sustentar narrativas diferentes da história contada pelas mídias corporativas. Deste modo, blogueiros, tuiteiros e tubeiros fizeram frente aos discursos dos veículos massivos através das imagens e falas produzidas por estas próprias mídias, na medida em que tinham o poder de atualizá-las de modo diferente, mesclando-as com suas próprias falas e imagens.

Temos neste debate dois pólos importantes. De um lado está em jogo a relação dos meios com as populações enquanto constituem um público; onde vai sobressair a questão do lugar que este público ocupa nesta relação. Trata-se de saber se ele é um consumidor relativamente passivo formado pelos produtos oferecidos pelo meio produtos estes que participam ativamente de sua formação cultural conformando sua subjetividade -; ou se o público participa como um usuário, determinando ativamente os produtos de sua própria formação.
Nasce daí a noção de que um amplo monitoramento e uma incessante vigilância devem fazer parte desta relação, pois aí estaria em jogo a formação dos sujeitos sociais e o comando da ação coletiva. Caberia às mídias cuidarem para os sujeitos fazerem parte da renovação da demanda social; seja preenchendo os papéis necessários à continuação da sociedade, seja querendo os produtos e serviços oferecidos pelas empresas. Caberia ao público não abdicar de seu lugar ativo em sua própria formação, rejeitando tudo o que pudesse subjugá-lo ou submetê-lo aos ditames da soberania social em detrimento da formação de sua subjetividade. São questões do saber cultural e do poder governamental envoltas na comunicação social (Antoun, 2009).

Mas no outro pólo está a relação do sujeito com a verdade contida ou ausente no meio aonde ele vai se formar. Trata-se de pensar quais chances ele tem de desenvolver uma subjetividade própria, de pôr em questão as escolhas que o meio lhe oferece ou interdita em função de tornar-se este ou aquele sujeito (Foucault, 2004, p. 253-280). Um meio perverso recusaria ao sujeito qualquer chance de se furtar a um destino social tornado provável que o aguardasse e lhe acenasse antes mesmo de seu nascimento.

A questão reconsiderada nesta perspectiva nos faz perceber o envolvimento da questão da justiça neste jogo do sujeito com a verdade de sua própria formação. Um meio de formação que predeterminasse completamente o sujeito seria totalmente injusto; o destino do sujeito teria sido escrito muito antes dele vir a existir e as narrativas de sua história sempre desembocariam em um certo grupo de resultados pré existentes ao seu surgimento (Deleuze, 1991, p. 93-116).

\section{Multimídias: dos meios de informação aos meios de coordenação}

Assim, a narrativa noticiosa, que sempre esteve atrelada àqueles que detinham a capacidade de irradiar informação (a imprensa), hoje está em todos os lugares virtuais, que se comportam cada vez mais como mídias de multidão (multimídias), ou seja, mídias cujas produções se dão de forma articulada e cooperativa, cujo produto final é exibido de forma pública e livre, para públicos específicos, que ao mesmo tempo, são mídias para outros públicos.

A natureza das multimídias é de portar uma linguagem desencarnada da mediação da mídia irradiada, desorganizando o modo tradicional da 
notícia, ao mesmo tempo em que elas organizam uma linguagem cooperativa, dialógica, múltipla e comum. Esta linguagem vai criar uma onda integrada, revelando as perspectivas independentes de opinião. Talvez o exemplo atual mais amadurecido seja o do que aconteceu nos conflitos iranianos ocorridos após a reeleição de Ahmadinejad. O exemplo ilustra como a biopolítica das multi-mídias sofre tentativas de bloqueios do poder soberano, do poder disciplinar, do biopoder, ao mesmo tempo em que excede todos eles através da potência coordenadora da comunicação.

O caso é por demais conhecido. Em 12 de junho, após derrota nas urnas, Hossein Mousavi reinvindica a vitória, acusando governo de fraudar as eleições, beneficiando assim o candidato da situação, Ahmadinejad. Um dia depois do resultado, ao mesmo tempo, nas ruas de Teerã, enquanto os apoiadores de Ahmadinejad comemoram a vitória, os de Mousavi, convocados via sms, entram em choque com a polícia.

O resultado dos conflitos, no outro dia, foi a suspensão da rede de internet e de telefonia móvel, numa tentativa de desacelera o processo de socialização e mobilização dos militantes. No contra ataque, hackers passam a oferecer endereço de proxy via direct message no Twitter, reconectando a cibercultura iraniana, que estava sem acesso aos serviços de telefonia local. A partir daí a internet torna-se o locus da informação e do compartilhamento de opinião sobre a insurgência iraniana. E o caso virará paradigma na história da comunicação por demonstrar que a narração dos acontecimentos públicos na web não prescinde de um encadeamento com a mídia irradiada, mas somente um entrelaçamento com a esfera de publicação dos próprios públicos das redes e mídias sociais online.

Essa invenção biopolítica criou um novo uso para a web, a cobertura jornalística p2p das multimídias, em tempo real, baseada na hashtag, que será massificada através de seus para descrever micro acontecimentos cotidianos e grandes eventos internacionais. Não se tratava de participação, senão da construção de mídia livres e autônomas.

No Twitter a multidão coopera adotando a hashtag ${ }^{1}$ \#iranelection. São 220 mil tweets/dia usando a palavra-chave, distribuindo fotos, vídeos, textos, áudios, enfim, toda uma gama de registros históricos que nenhum grupo de mídia detinha.
Em pouco tempo, o movimento era tão grande que, revoltados contra a pouca informação sobre os acontecimentos veiculada pela CNN, os usuários começaram a usar uma hashtag adicional: a \#cnnfail, empurrando a rede de televisão americana para dentro da agenda midiática da multidão.

"Tiger Woods não é a história mais importante no mundo hoje \#CNNfail"2, afirmava o tuiteiro @lilobri, que criticava a insistência do canal de tevê em valorizar escândalos sexuais nos EUA no lugar de uma cobertura ampla sobre os assuntos globais. O \#cnnfail foi subproduto de um dos maiores temores do biopoder online, o comentário.

Este geralmente tem a função de revelar não somente omissões, mas as posições políticas, históricas e de classe do poder em rede. Não é à toa que os mídias tradicionais só liberam comentários naquelas reportagens que agitam os fascistas ou acalmam os ingênuos. A partir do momento que o comentário ganha mais audiência do que a própria agenda midiática, as mídias são forçadas a mencioná-los, quando não investigá-los.

Na prática, a narrativa noticiosa baseada em hashtags foi utilizada para troca de informação mútua, organização tática dos protestos, globalização dos fatos, localização de testemunhas/fontes, relatos multimídia de registros do cotidiano, promoção de ideologias, conversação social e agendamento da mídia.

No caso da eleição iraniana, como em outros casos, a multidão conectada executa um panóptico às avessas, em que as celas não param de monitorar a torre, disputando com a mídia corporativa a primazia da comunicação. Esse monitoramento vigilante contínuo das celas, numa cobertura multi-mídias, serve como um depurador da construção social dos acontecimentos na grande imprensa, em proveito próprio, por fazer esta martelar as idéias comuns que a multidão defende.

\section{Considerações finais}

A experiência iraniana, que depois se repetirá, em outros casos, como o de \#honduras, \#michaeljackson, \#forasarney, \#haiti, provocou uma nova linguagem jornalística, a "hashtag storytelling", uma espécie de Napster da narrati- 
va noticiosa, em que os internautas têm acesso a tudo o que se publica na rede, de forma direta, ponto a ponto, de baixo pra cima, criando e participando um grande mural conversacional e uma comunidade virtual de notícia.

$\mathrm{Na}$ prática, a narrativa noticiosa baseada em hashtags foi utilizada para troca de informação mútua, organização tática dos protestos, globalização dos fatos, localização de testemunhas/ fontes, relatos multimídia de registros do cotidiano, promoção de ideologias, conversação social e agendamento da mídia.

Os protestos no Irã foram derrotados. E não houve nenhuma revolução tão euforicamente alastrada pelo mundo ocidental. Mas o saldo biopolítico foi o de colaborar com a paisagem das multimídias que excedem a "infracensura" dos controles e bloqueios da rede. E diferente dos veículos tradicionais de imprensa, que são meios de informação, o que a biopolítica da multidão online tem empregado é a transformação das mídias sociais em mídias de coordenação.

E mais do que isso, a "narrativa dos muitos", com uso de hashtag, ultrapassa e reinventa a noção breaking news. Ela traz a autonomia para o modelo da mídia online, porque faz da vida e da história as condutoras do tempo real, ao não paralisar o tempo, mas apropriar-se dele e reterritorializá-lo com a narrativa coordenadora da ação coletiva.

\section{REFERÊNCIAS}

ANDERSON, Chris. A cauda longa: do mercado de massa para o mercado de nicho. Rio de Janeiro: Campus, 2006.

ANTOUN, Henrique. Web 2.0 e o Futuro da Sociedade Cibercultural. Lugar Comum - Estudos de Mídia, Cultura e Democracia, v. 14, n. 27, 2009. p. 235-245.

. De Uma Teia à Outra: A explosão do comum e o surgimento da vigilância participativa. In: ANTOUN, Henrique (Org.). Web 2.0: Participação e vigilância na era da comunicação distribuída. Rio de Janeiro: Mauad, 2008. p. 11-28.

. O Poder da Comunicação e o Jogo das Parcerias na Cibercultura. Revista Fronteira. São Leopoldo/RS, v. VI, n. 2, 2004. p. 67-86.

ANTOUN, Henrique; LEMOS, Ana Carla; PECINI, André Custódio. Código e luta por autonomia na comunicação em rede. In: FREIRE FILHO, João; HERSCHMANN, Micael (Orgs.), Novos rumos da cultura da mídia: indústrias, produtos, audiências. Rio de janeiro: Mauad, 2007. p. 263-290.

ARQUILLA, John; RONFELDT, David. Networks, Netwars and the Fight for the Future. First Monday, v. 6, n. 10, out. 2001.

BARBROOK, Richard. A regulamentação da liberdade: liberdade de expressão, liberdade de comércio e liberdade de dádiva na rede. In: COCCO, Giuseppe et al. Capitalismo cognitivo. Rio de Janeiro: DP\&A, 2003.
BAUWENS, Michel. The Political Economy of peer production. 1000 Days of Theory, n. 26, 2005. Disponível em: $<$ http://www.ctheory.net/articles.aspx?id=499>. Acesso em: 01 ago. 2008.

BENKLER, Yochai. The wealth of networks: how social production transforms markets and freedom. Nova Iorque: Yale University Press, 2006.

CASTELLS, Manuel. Communication Power. Nova Iorque: Oxford University Press, 2009

CLEAVER, Harry. Computer-linked social movements and global threat to capitalism. Texas: Texas University, 1999. Disponível em: <http://www.eco.utexas.edu/ hmcleave/polnet.html>. Acesso em: 04 ago. 2008.

DELEUZE, Gilles. Conversações. Rio de Janeiro:34 Letras, 1992. 1991 A Dobra: Leibniz e o barroco. São Paulo: Papirus,

Foucault. São Paulo: Brasiliense, 1988.

DELEUZE, Gilles; GUATTARI, Felix. Mille Plateaux. Paris: Minuit, 1980.

FOUCAULT, Michel. Le Courage de la Vérité. Paris: Gallimard, 2009.

Le Gouvernement de Soi et des Autres. Paris: Gallimard, 2008b.

2004. A Hermenêutica do Sujeito. São Paulo: Martins Fontes, tes, 2008a.

O Nascimento da Biopolítica. São Paulo: Martins Fon-

Vigiar e Punir. Rio de Janeiro: Vozes, 1977.

GALLOWAY, Alex. Protocol: how control exists after decentralization. Cambridge: MIT Press, 2004.

GALVÃO, Alexander Patez; SILVA, Gerardo; COCCO, Giuseppe. Capitalismo Cognitivo: trabalho, redes e inovação. Rio de Janeiro: DP\&A, 2003.

JENKINS, Henry. Fans, Bloggers, and Gamers: Media Consumers in a Digital Age. Nova Iorque: New York University Press, 2006.

JOHNSON, Steven. Cultura da interface: como o computador transforma nossa maneira de criar e comunicar. Rio de Janeiro: J. Zahar, 2001.

KOLLOCK, Peter. Social Dilemmas: The Anatomy of Cooperation. Annual Review of Sociology, n. 24, 1998, p. 183214.

LAZZARATO, Maurizio; NEGRI, Antonio. Trabalho Imaterial: formas de vida e produção de subjetividade. Rio de Janeiro: DP\&A, 2001.

LESSIG, Lawrence. Code and other laws of cyberspace. Nova Iorque: Basic Books, 1999.

Free Culture. New York: The Penguin Press, 2004.

LEVINE, Rick; LOCKE, Christopher; SEARLS, Doc; WEINBERGER, David. The Cluetrain Manifesto: the end of business as usual. Cambridge: Perseus, 2000.

MALINI, Fábio. Modelos de colaboração nos meios sociais da internet: uma análise a partir dos portais de jornalismo participativo. In: ANTOUN, Henrique (Org.). Web 2.0: participação e vigilância na era da comunicação distribuída. Rio de Janeiro: Mauad X, 2008. 
NEGRI, Antonio; HARDT, Michael. Commonwealth. Cambridge, MA: The Belknap Press, 2009.

. Multidão: Guerra e democracia na era do Império. Rio de Janeiro: Record, 2005.

. Império. Rio de Janeiro: Record. 2001.

PRETTO, Nelson de Luca; SILVEIRA, Sérgio Amadeu da. Além das Redes de Colaboração: internet, diversidade cultural e tecnologias do poder. Salvador: EDUFBA, 2008.

RHEINGOLD, Howard. Smart Mobs: the next social revolution. Cambridge: Perseus, 2002.

RUSHKOFF, Douglas. Coercion: why we listen to what "they" say. Nova Iorque: Riverhead Books, 1999.
TERRANOVA, Tiziana. Network Culture: Politics for the Information Age. Londres: Pluto Press, 2004.

\section{NOTAS}

1 Palavra chave que funciona como metadados, estimulando a agregação de upgrades pelos agentes de busca. Para o usuário, mostra as atualizações em tempo real sobre determinada temática, o que facilita a leitura de tendências de opinião na rede.

2 Tradução nossa para "Tiger Woods is NOT the most important story in the world today \#CNNfail" Sobre o \#cnnfail, acesse http://cnnfail.com/. 